\title{
Residual Stress Determination of Ductile Cast Iron by means of Neutron Diffraction
}

\author{
F. Smith ${ }^{1, a^{*}}$, J. Markgraaff ${ }^{1, b}$, D.Marais ${ }^{2, c}$ and A.M. Venter ${ }^{2, d}$ \\ ${ }^{1}$ North-West University, School of Mechanical and Nuclear engineering \\ ${ }^{2}$ Research and Development Division, Necsa SOC Limited, Pretoria, South Africa \\ aswysnwu@yahoo.com, bjohan.markgraaff@nwu.co.za, ${ }^{c}$ deon.marais@necsa.co.za, \\ dandrew.venter@necsa.co.za
}

Keywords: Valves, Ductile Cast Iron, Residual Stress, Neutron Diffraction, MAGMASOFT ${ }^{\circ}$

\begin{abstract}
A study was undertaken to simulate the casting process, using simulation software, of a ductile iron casting (for use as a valve body) and in doing so to determine the order of residual stress and experimentally verify the simulation results. The simulation was carried out using MAGMASOFT ${ }^{\circledR}$ and the residual stress results verified using neutron diffraction. The measured residual stress results were found to compare favourably with the simulation predictions.
\end{abstract}

\section{Introduction}

Mechanical valves play an essential part in industrial processes and other related systems. South African manufacturers must compete with international counterparts to supply affordable highquality valves to clients. Production costs of valves can be reduced by optimising the design to use fewer raw materials.

Mechanical valves are most commonly produced from ductile cast iron. During the casting process, residual stresses are introduced in the component. By controlling the residual stresses within mechanical components, premature failure can be prevented.

Computer aided programmes, such as FEMLAB 3.1i and other, can be used to simulate certain aspects of the casting process. MAGMASOFT ${ }^{\circledR}$ with the module MAGMAstress aims to simulate the casting process and also predicts the presence of residual stress [1].

\section{Method}

The neutron diffraction analysis technique was chosen as the experimental verification method due to its non-destructive nature and the ability to penetrate deep within the material.

Sample selection. Due to the geometric complexities associated with valves, trees consisting of simple cylindrical shaped branches were chosen for this investigation and verification exercise. The same material (EN-GJS-400) as used in ductile iron valves manufactured in South Africa, was used.

Simulation. The cast tree (Fig. 1) consists of cylindrical branches with a height of $150 \mathrm{~mm}$ and different base diameters $(15-30 \mathrm{~mm})$. The residual stresses within the branches were simulated with MAGMASOFT ${ }^{\circledR}$ using a Solidworks model. Additional simulations were then carried out using boundary conditions which resembled heat treated branches and machined branches respectively (Fig. 2). 


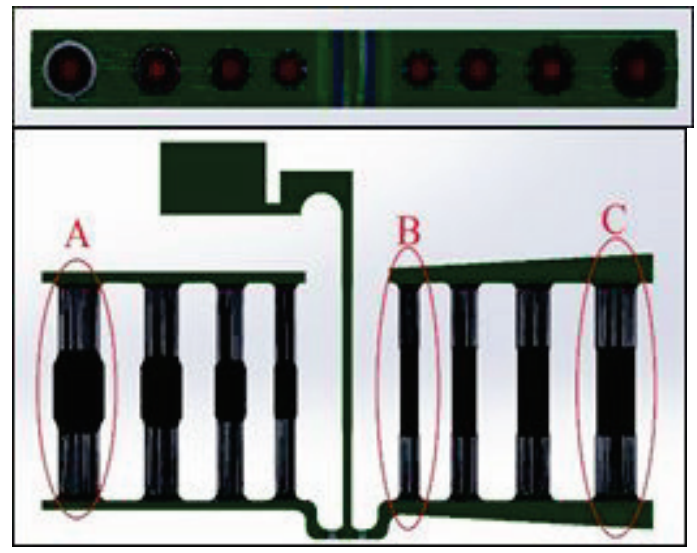

Fig. 1: (a) Sectional cut top view showing the 8 cylindrical branches' diameters and (b) front view of the ductile iron cast tree $3 D$ model.

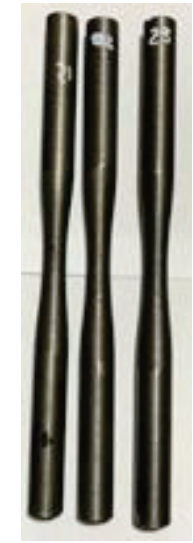

Fig. 2: Machined branches.

Simulations were conducted on the following branches with boundary conditions given in Table 1:

1. Branches simulated without runners (V2) (Fig. 4);

2. Branches simulated without runners subjected to a heat treatment process (V3) (Fig. 6); and

3. Branches simulated without runners subjected to machining (V4) (Fig. 9).

Table 1: MAGMASOFT®

Simulation Information.

\begin{tabular}{|l|l|}
\hline Pouring temp. $\left[{ }^{\circ} \mathrm{C}\right]$ & 1400 \\
\hline Shakeout temp. $\left[{ }^{\circ} \mathrm{C}\right]$ & 500 \\
\hline Pouring height $[\mathrm{mm}]$ & 30 \\
\hline Mould sand & Furan Sand \\
\hline $\begin{array}{l}\text { Inlet size diameter } \\
{[\mathrm{mm}]}\end{array}$ & 24 \\
\hline Pouring time $[\mathrm{sec}]$ & 13 \\
\hline \multirow{2}{*}{$\begin{array}{l}\text { Machining size } \\
{[\mathrm{mm}]}\end{array}$} & Length: 120 \\
\cline { 2 - 2 } & $\begin{array}{l}\text { Diameter: } 11.8-8- \\
11.8 \text { (see Fig. } 2)\end{array}$ \\
\hline \multirow{5}{*}{ Heat treatment } & $\begin{array}{l}1 . \text { Heated to } 600{ }^{\circ} \mathrm{C} \\
\text { over } 30 \text { min }\end{array}$ \\
\cline { 2 - 2 } & $\begin{array}{c}2 . \text { Kept at } 600{ }^{\circ} \mathrm{C} \text { for } \\
60 \text { min }\end{array}$ \\
\cline { 2 - 2 } & $\begin{array}{c}3 . \text { Furnace cooled to } \\
150{ }^{\circ} \mathrm{C} \text { over } 270 \text { min }\end{array}$ \\
\cline { 2 - 2 } & $\begin{array}{c}4 . \text { Air cooled to room } \\
\text { temperature }\end{array}$ \\
\hline
\end{tabular}

Table 2: Neutron diffraction measurement information.

\begin{tabular}{|c|c|c|}
\hline \multicolumn{2}{|c|}{ Gauge volume $\left[\mathrm{mm}^{3}\right]$} & $2 \times 2 \times 2$ \\
\hline \multicolumn{2}{|c|}{$\begin{array}{l}\text { Slit positioning from centre of } \\
\text { rotation }[\mathrm{mm}]\end{array}$} & 55 \\
\hline \multicolumn{2}{|c|}{ Wavelength $[\AA]$} & 1.67 \\
\hline \multicolumn{2}{|c|}{ Diffraction peak measured } & $\mathrm{Fe}(211)$ \\
\hline \multicolumn{2}{|c|}{$2 \Theta$ detector angle $\left[^{\circ}\right]$} & 90 \\
\hline \multirow{3}{*}{$\begin{array}{l}\text { Measurement time per } \\
\text { position }[\mathrm{sec}]\end{array}$} & $\mathrm{V} 2$ & 1200 \\
\hline & V3 & 3600 \\
\hline & V4 & 120 \\
\hline
\end{tabular}

Verification. Three identical trees were cast using EN-GJS-400 ductile cast iron to replicate the simulated models. Three branches, A, B and C (Fig. 1), with the highest simulated residual stress values were cut from two of the trees.

The cavities MAGMASOFT ${ }^{\circledR}$ predicted were investigated by means of X-Ray Tomography using the facilities at the South African Nuclear Energy Corporation (Necsa) SOC Limited [2]. After model reconstruction (shown in Fig 3.), it was established that there were no cavities present in the cast sample. The neutron diffraction measurements could therefore be performed without correcting for spurious strains due to partial gauge volume illumination. 


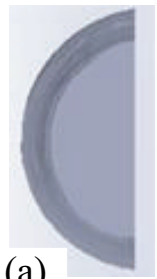

(a)

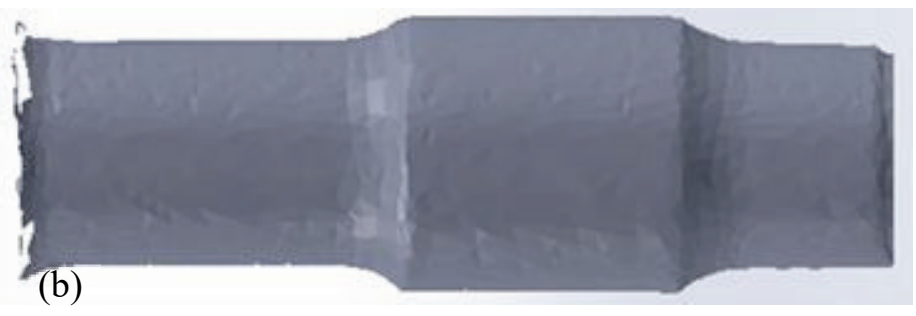

Fig 3: (a) Top and (b)

front cut view of the reconstructed solid obtained by means of $X$-ray tomography.

The residual strains were then measured at the MPISI [3] angular dispersive neutron strain scanner situated at the SAFARI-1 research reactor of Necsa. The average $d$-spacing values measured of each branch, were used as the $\mathrm{d}_{0}$ (reference) values for the measurements. Strains were then converted to residual stresses (Eq. 1) [4] along the measurement lines of the individual branches (Fig. 4, 6 and 9) and compared with the MAGMASOFT ${ }^{\circledR}$ simulation results. Information regarding the neutron diffraction measurements is summarized in Table 2.

$$
\sigma_{z}=\frac{E}{(1+v)(1-2 v)}\left[(1-v) \varepsilon_{z}+v\left(\varepsilon_{x}+\varepsilon_{y}\right)\right]
$$

\section{Results}

The stress values were extracted of the z-direction stress components along the z-axis (vertical axis) direction (Fig. 4) as this was where MAGMASOFT ${ }^{\circledR}$ predicted the highest order of residual stress. The residual strain measurements were obtained at 30 coordinates, in comparison with 100 coordinates MAGMASOFT ${ }^{\circledR}$ used, along the z-axis direction.

Graphs show the difference between the MAGMASOFT ${ }^{\circledR}$ and neutron diffraction values for every simulation done. Comparison graphs of (V2) vs (V3) and (V2) vs (V4) are also shown. MAGMASOFT ${ }^{\circledR}$ and neutron diffraction results of only Branch A will be shown.

Branches simulated without runners (V2)

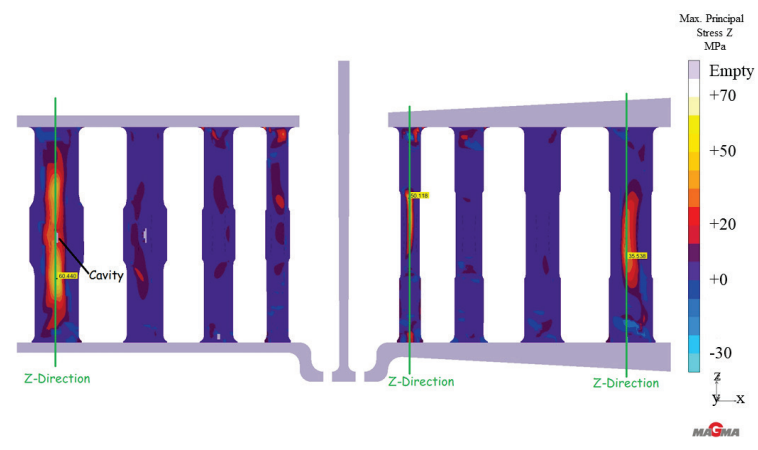

Fig. 4: MAGMASOFT® Z-component residual stress results - Simulation (V2) and measurement directions shown.

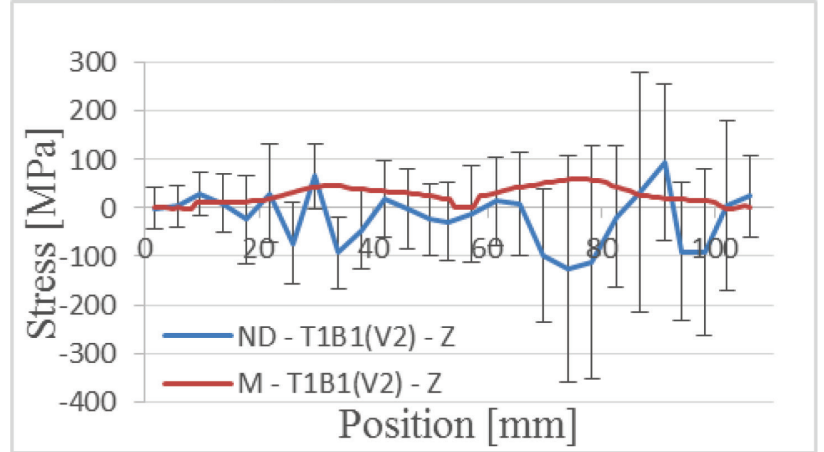

Fig. 5: MAGMASOFT ${ }^{\circledR}$ vs Neutron Diffraction $Z$-component residual stress results (V2). 
Heat treated branches (V3)

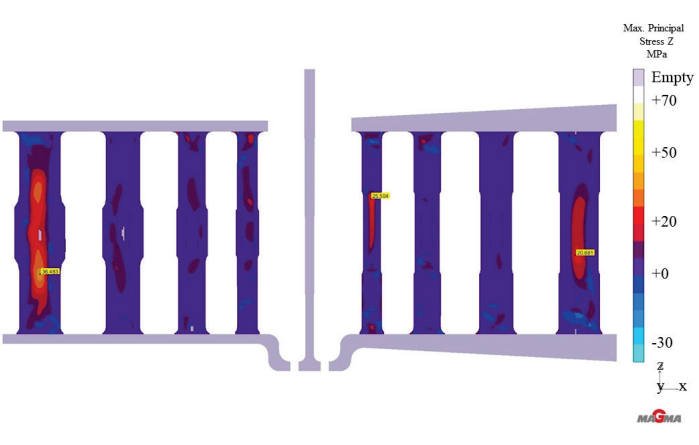

Fig. 6: MAGMASOFT® Z-component residual stress results - Simulation (V3) heat treated.

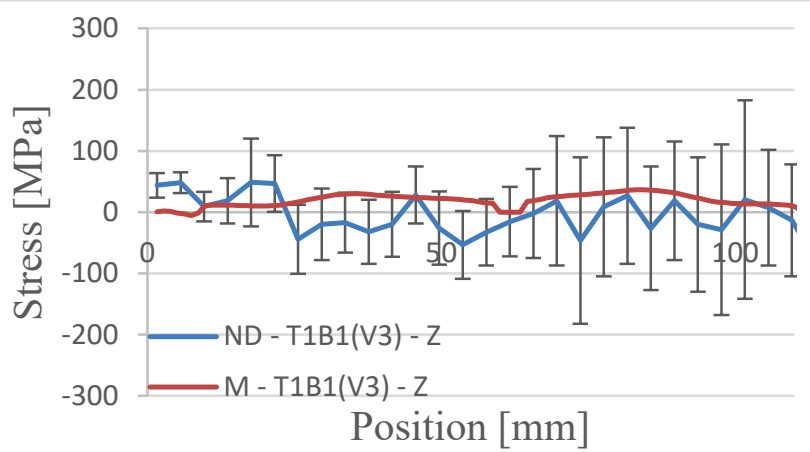

Fig. 7: MAGMASOFT® vs Neutron Diffraction Zcomponent residual stress results (V3) heat treated.

Heat Treated Branches: Stress vs Position

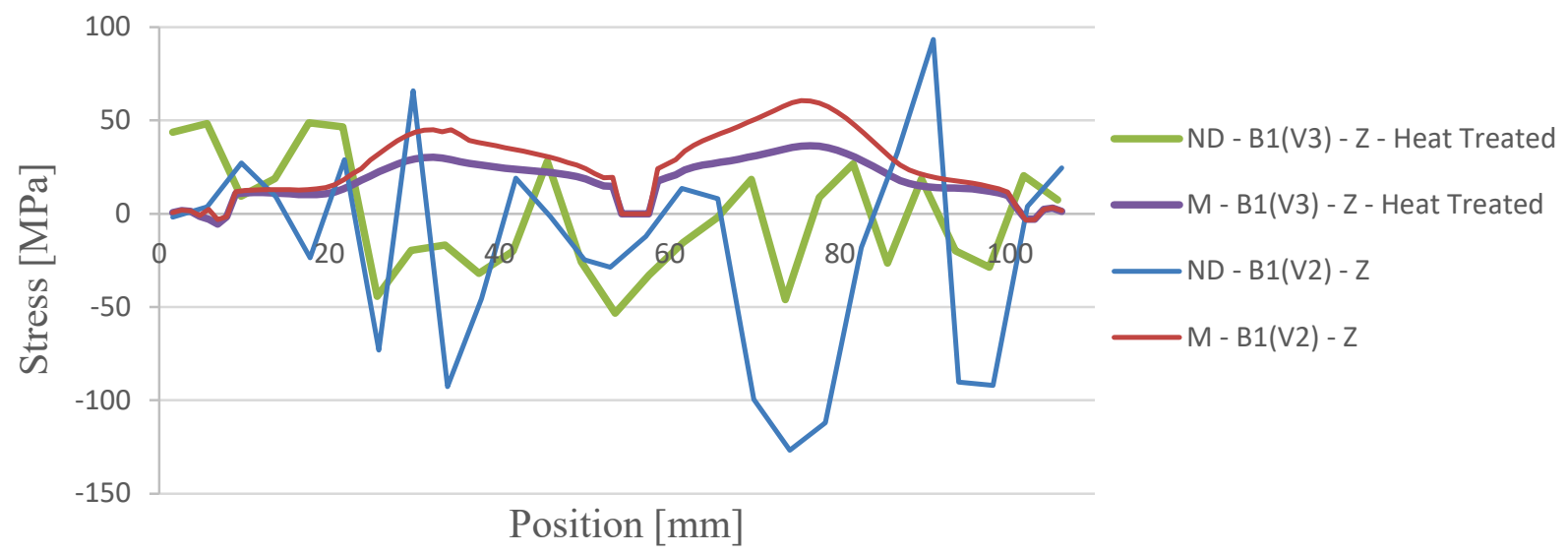

Fig. 8: Comparison of Z-component residual stress results between (V2) and (V3).

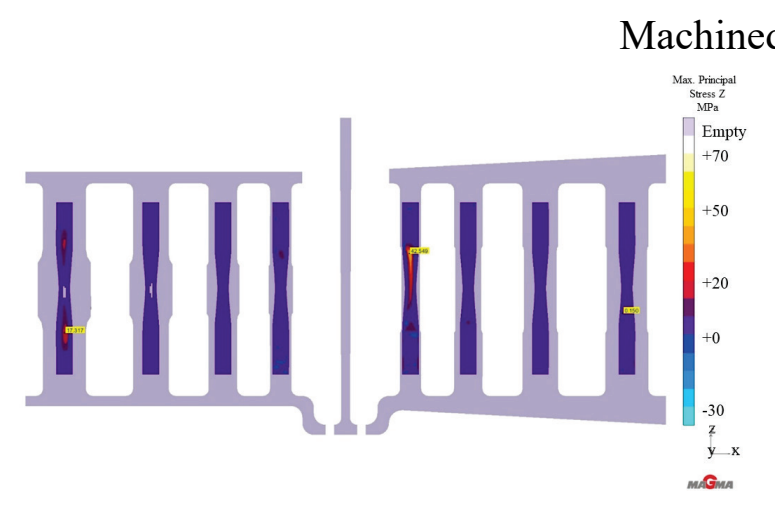

Fig. 9: MAGMASOFT $®$ Z-component residual stress results - Simulation (V4) machined.

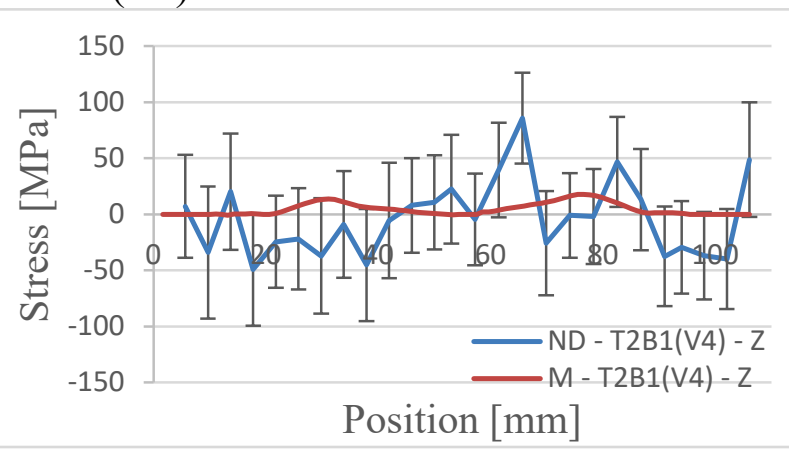

Fig. 10: MAGMASOFT ${ }^{\circledR}$ vs Neutron Diffraction

$Z$-component residual stress results (V4) machined. 


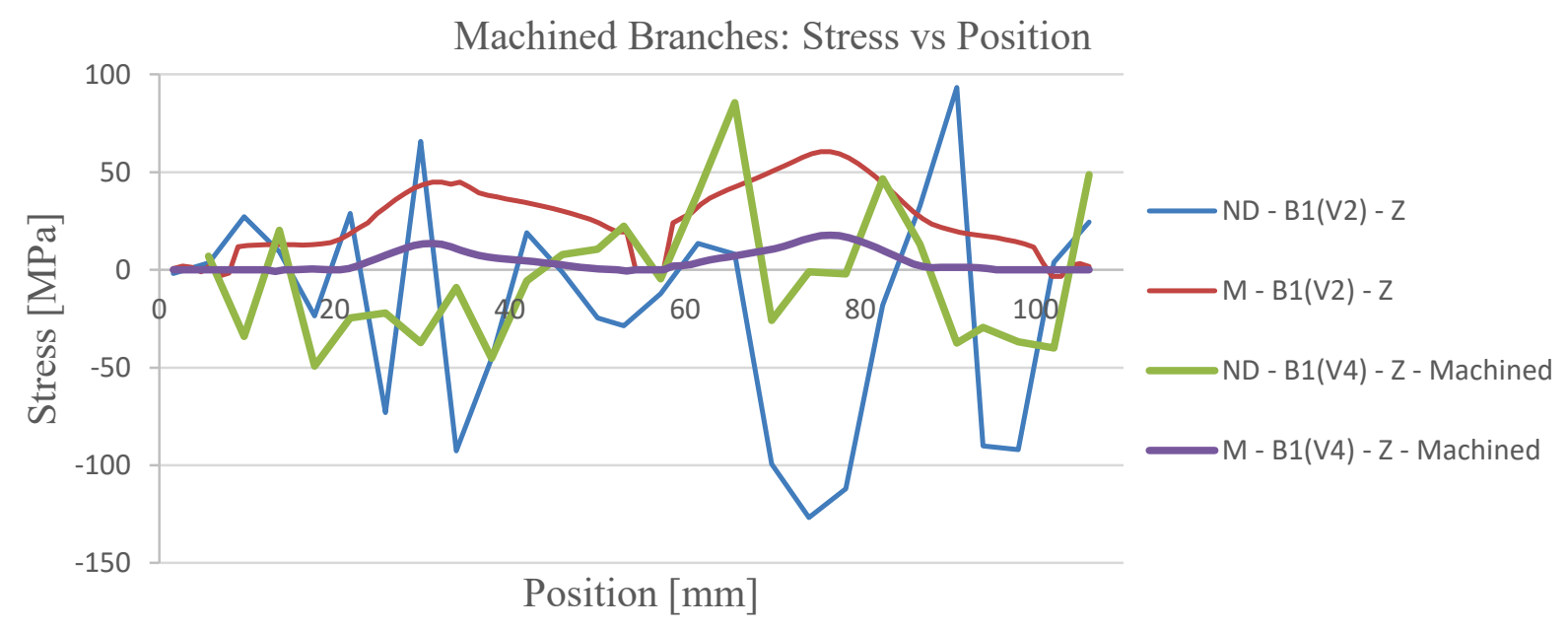

Fig. 11: Comparison of Z-component residual stress results between (V2) and (V4).

\section{Discussion}

Considering the X-ray tomography results, no cavities were observed, thus the neutron diffraction measurements could continue normally without any corrections.

With the data obtained trends between MAGMASOFT ${ }^{\circledR}$ and the neutron diffraction results (Figs. 5, 7 and 10) are apparent, even though the values do not match very well. Most of the values fall within the experimental error limit.

When analyzing the data, peaks can be observed in the neutron diffraction measurement results, whereas the MAGMASOFT $®$ results have even curves. This is due to the measurements not having as much data points as the MAGMASOFT $®$ simulation results.

When considering the heat treated and machined results (Figs. 8 and 11), both MAGMASOFT ${ }^{\circledR}$ and neutron diffraction predicted a decrease in residual stress.

Possible reasons for the inaccuracy of the residual stress results:

- The cope and the drag of the mould was not clamped and sealed correctly causing a leak through the mould forming a large flash, which possibly influenced the residual stress results.

- The material used for casting could have differed slightly in composition to that specified in the simulation.

\section{Conclusion}

The data collected suggests that MAGMASOFT $®$ can be used to accurately simulate the residual stress in the casting process and more specifically simulate residual stress in valves as it uses conservative measures.

To fully verify MAGMASOFT ${ }^{\circledR}$, samples should be made consisting of much higher residual stress which can be more accurately determined by means of neutron diffraction.

The neutron diffraction statistics could also be improved by means of increasing the measurement time per position, thus decreasing the experimental errors. 


\section{References}

[1] Information on http://www.magmasoft.com/en/solutions/MAGMA_5.htm

[2] J.W. Hoffman and F.C. de Beer, Characteristics of the Micro-Focus X-ray Tomography Facility (MIXRAD) at Necsa in South Africa, 18th World Conference on Non-destructive Testing. (2001)

[3] A.M. Venter, P.R. van Heerden, D. Marais and J.C. Raaths, MPISI: The neutron strain scanner Materials Probe for Internal Strain Investigations at the SAFARI-1 research reactor, Physica B, In press. https://doi.org/10.1016/j.physb.2017.12.011

[4] G.A. Webster and R.C. Wimpory, Non-destructive measurement of residual stress by neutron diffraction, J. Mater. Process. Technol. $117 \quad$ (2001) 395-399. https://doi.org/10.1016/S0924-0136(01)00802-0 